\title{
Evaluation of taste, total phenols and antioxidant for fresh, roasted, shade dried and boiled leaves of edible Arum palaestinum Bioss
}

\author{
Mohammad Qneibi ${ }^{1 *}$, Nidal Jaradat ${ }^{2}$, Abed Naser Zaid ${ }^{2}$, Nawaf Abu-Khalaf ${ }^{3}$, Abdel - Razzak Natsheh ${ }^{4}$, Fatima Hussein ${ }^{2}$ \\ Department of Biomedical Sciences, Faculty of Medicine and Health Sciences, An-Najah National University, Nablus, Palestine. \\ Department of Pharmacy, Faculty of Medicine and Health Sciences, An-Najah National University, Nablus, Palestine. \\ Department of Agricultural and Biological Engineering, Faculty of Engineering, Palestine Technical University, Kadoorie, Palestine. \\ 4 Department of Computer Information Systems, Faculty of Engineering and Information Technology, An-Najah National University, Nablus, Palestine.
}

\begin{abstract}
Arum palaestinum is one of the famous wild plants that have been used since the ancient time in the Palestinian folk food and medicine. However, it needs particular cooking steps to decrease its numbing taste. We investigated the impact of cooking, measures on taste, total phenols and antioxidant activity of wild A. palaestinum by using an Alpha-Astree Electronic tongue (ET), which is used for food taste assessment. In this study, the A. palaestinum was cooked in different ways. We used Folin Ciocalteu's process to compare total phenols, where radical scavenging assay was used to evaluate the antioxidant activity using 2, 2-diphenyl1-picrylhydrazyl-hydrate (DPPH). Our results showed that a very significant discrimination of the samples with different distances between groups (p-values $<0.001$ ) in the ET results coupled with the principal component analysis $(\mathrm{PCA})$. The samples were in the following order in term of numbing taste: Fresh $>$ dried $>$ cooked. Moreover, the pattern discrimination index between (A and C), ( $\mathrm{B}$ and $\mathrm{C}$ ) and (A and $\mathrm{B}$ ) were $88 \%, 96.36 \%$, and $98 \%$, respectively, which suggests that $\mathrm{C}$ and $\mathrm{A}$ are the most similar preparations in term of taste, while B is the worst one. Our results reveal that the cooking and dried A. palaestinum showed a lower numbing taste by ET, while the antioxidant activities showed a marked correlation with the total phenolic contents. As a result, we concluded that the oven dried preparing method (home roasting) for A. palaestinum is the most efficient method for consumption or preparing bioactive supplements for nutraceutical and pharmaceutical supplements.
\end{abstract}

KEYWORDS: Arum palaestinum; antioxidants; total phenolic content; edible wild plants

\section{INTRODUCTION}

High daily consumption of plants which are rich in active antioxidant compounds mainly phenols has been assured to be correlated with lower mortality rate and incidence of several degenerative diseases such as diabetes, cardiovascular diseases, and cancer $[1,2]$.

Phytochemicals as phenols are commonly founded in both edible and non-edible plants, and they have been reported to have various pharmacological activities, including antioxidant $[3,4]$.

Edible plants crude extracts plentiful in phenols are increasing of interest in the food and pharmaceutical industrial supplements because they slow oxidative degradation of fats and oils thereby improve the healthy nutritional value and the quality of food [5].

The value of the antioxidant components of edible plants that improve health style and prevent cancer and coronary heart disease is also increasing the interest among consumers, scientists, food supplements and pharmaceutical

Received: $\quad$ 04.10.2017 / Accepted: 29.11.2017

Corresponding Author: Mohammad Qneibi

E-mail: mqneibi@najah.edu

Phone: +970 (9) 2345113

ORCID No: https://orcid.org/0000-0002-0702-7834 formulations manufacturers, and recent trends of adequate nutrition with specific health effects is raising [1].

Edible wild herbs have always played a significant role in the folk traditions of the Mediterranean region [2]. In the past decade, numerous scientific experiments have evaluated the gathering and consumption of edible wild plants in several countries in the Mediterranean region [6] such as Cyprus [3], Greece [4], Spain [5], Italy [7], Turkey [8], and France [9].

Around 31 species of plants that belong to genus Solomon's lily were classified in nature. One of the most traditional ones is Arum palaestinum Boiss. (Solomon's lily). This species is a perennial herbaceous plant belonging to the Araceae family. This family has about 1000 members distributed mainly in the Mediterranean regions. A. palaestinum (Life in Arabic) is also known as Solomon's Lily, Black Calla, Priest's Hood and Palestinian Arum. This plant grows wildly in Palestine, Jordan, Lebanon, and Syria [10]. Various species of Solomon's lily was and still used as food and as folk medicine in the Mediterranean Sea Regions [11].

How to cite this article: Qneibi M, Jaradat N, Zaid AN, Abu-Khalaf N, Natsheh A, Hussein F. Evaluation of taste, total phenols and antioxidant for fresh, roasted, shade dried and boiled leaves of edible Arum palaestinum Bioss. Marmara Pharm J. 2018; 22 (1): 52-58. 
In Palestine, a large number of wild edible herbals are widely distributed throughout the country and consumed in various ways. For example, the leave of Arum palaestinum, which is used by herbal practitioners and local rural healers in the treatment of several diseases such as a cough, constipation, heartburn, urinary tract infections, cancer, diabetes, hemorrhoids, atherosclerosis, ameba and kill worms in the gastrointestinal tract $[12,13]$.

The phytochemical screening of Solomon's lily plants showed that these plants contain alkaloids, polyphenols, glycosides (flavonoids, saponin, and cyanogenic groups), proanthocyanidins, 2-heptanone, indoles, p-cresol, (E)caryophyllene, monoterpenes, and two unidentified sesquiterpenes and lectin $[14,15]$. Isoprenoids or terpenoids consist mainly of isoprene units and have antibacterial, antifungal, antiviral and antiprotozoal activities [16]. Also, the isolation and structural elucidation of a novel pyrrole alkaloid were investigated and showed it has anticancer activity against breast carcinoma cells, hepatocarcinoma, and lymphoblastic leukemia $[17,18]$.

However, this plant has a strong and fastidious numbing taste. As a result, the Palestinian folk food dried the Solomon's lily and cooked to minimize this drawback. Nonetheless, this step may negatively impact the phytochemical and therapeutic outcome of this plant. In this study, we attempted to assess the phytochemical activities of Solomon's lily before and after being cooked, where the taste of the tested samples has been evaluated using Alpha-Astree electronic tongue (ET). The taste of Solomon's lily plays a significant role in patient compliance and consequently therapeutic effectiveness. Traditionally, the taste assessment of a food product is usually conducted on human panelists, yet this may be costly and time-consuming. Since then many reliable and predictive methods have been developed to evaluate food tastes in vitro [1-5, 7]. ET is considered one of the most useful and precise methods for this purpose. It consists some low-selective and cross-sensitive sensors and uses advanced mathematical procedures for signal processing based on the multivariate analysis, e.g., pattern recognition (PARC) and artificial neural networks (ANNs) [6, 8-10]. Also, it does not need sample preparation, where the same samples can be measured several times since there is no change in their characteristics after the first trial of measurements [11-13]. ET has been used in: (i) biotechnology applications, (ii) food industry, (iii) olive oil authentication and adulteration, (iii), and most importantly, oral pharmaceutical product evaluation [12, 14-23].

\section{RESULTS}

In the entire world, tremendous resources are being invested in diagnosis, prevention, and treatment of cancer and degenerative cardiovascular disease by using safety edible and medicinal plants [2].
Discovering and screening for potential anticancer and antioxidant agents from natural edible plants still in the recent time is the main scope for many of the nutraceutical and pharmaceutical institutions [3].

\subsection{Total phenols screening results for four Solomon's lily prepared samples}

Phytochemical phenols are class of secondary metabolic compounds found in the plants and have been approved that they have various physiological and biological activities including antibacterial, antiviral, anti-inflammatory, antiallergenic and antioxidant activities [24, 25].

The absorbance of standard compound (Gallic acid) at $\lambda_{\text {ma }}$ $=765 \mathrm{~nm}$ in Arum palaestinum presented in Table 1 and Figure 1.

Table 1. Absorbance of standard compound (Gallic acid)

\begin{tabular}{ll}
\hline Absorbance at $\lambda_{\max }=765 \mathrm{~nm}$ & Gallic acid concentration $(\mathrm{mg} / \mathrm{ml})$ \\
\hline 0.051 & 0.1 \\
0.099 & 0.2 \\
0.168 & 0.3 \\
0.231 & 0.4 \\
0.287 & 0.5 \\
0.544 & 1 \\
\hline
\end{tabular}

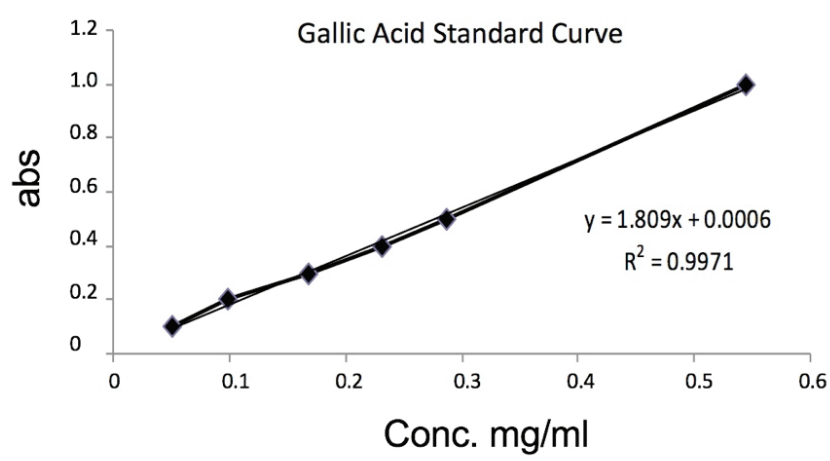

Figure 1. Standard calibration curve for gallic acid

Solomon's lily leaves four extracts (fresh, boiled, shade dried and oven dried) exhibited high phenolic contents as presented in Table 2. The highest total phenolic contents were in the fresh, and oven-dried Solomon's lily leaves were 53.07 mg GA/g extract, while the total phenolic contents in boiled Solomon's lily leaves was $24.05 \mathrm{mg}$ GA/g extract and the contents in shade dried Solomon's lily leaves was the lowest 
(17.14 mg GA/g extract) as shown in Figure 2. These results showed that the boiling process and shade drying methods of preparations damaging most of the phenolic contents in Solomon's lily leaves.

Table 2. Total phenolic contents in the fresh, boiled, shade dried and oven dried (roasted) Solomon's lily leaves

\begin{tabular}{ll}
\hline A. palaestinum extract & $\begin{array}{l}\text { Total phenolic contents } \\
(\mathrm{mg} \mathrm{GA} / \mathrm{g} \text { extract), } \pm \text { SD }\end{array}$ \\
\hline Fresh Solomon's lily extract & $53.07 \pm 0.12$ \\
Roasted (oven dried) Solomon's lily extract & $53.07 \pm 0.12$ \\
Boiled Solomon's lily extract & $24.05 \pm 0.32$ \\
Shade dried Solomon's lily extract & $17.14 \pm 0.22$ \\
\hline
\end{tabular}

SD stands for standard deviation

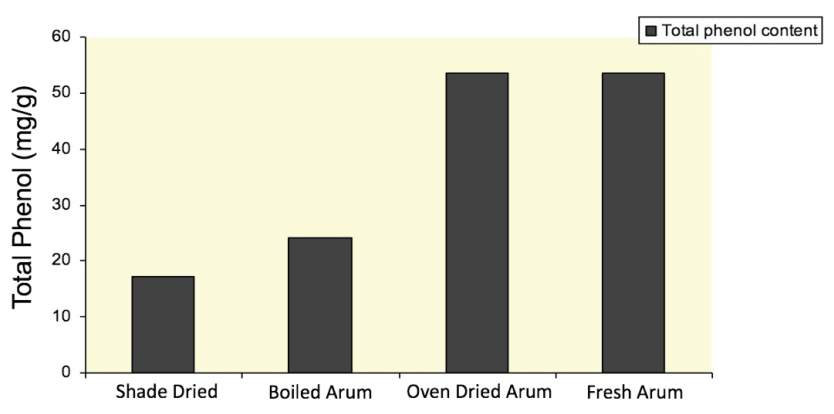

Figure 2. Total phenolic content of different A. palaestinum extracts

\subsection{In vitro antioxidant properties of the extraction}

DPPH has been utilized widely as a free radical to evaluate reducing compounds and it is a useful reagent for estimatinginvitro free radical scavenging activities of the phytochemicals. As shown in (Figure 2), all the four Solomon's lily prepared samples exhibited ratable scavenging properties against DPPH radicals and it was clear that the oven dried Solomon's lily leaves (roasting method of preparation) were proven to be the most powerful antioxidant with $\mathrm{IC}_{50}$ value $14.55 \pm 2.06$ $\mu \mathrm{g} / \mathrm{ml}$ (Table 3 and Figure 3), as their radical-scavenging activities were significantly different from any other kinds of Solomon's lily prepared methods. However, the shade dried samples exhibited the lowest radical scavenging activity with $\mathrm{IC}_{50}$ value $63.09 \pm 2.38 \mu \mathrm{g} / \mathrm{ml}$ comparing to Trolox standard compound which had IC $_{50}$ value $2.1 \pm 2.03 \mu \mathrm{g} / \mathrm{ml}$.
Table 3. $\mathrm{IC}_{50}$ value of different A. palaestinum leaves extracts

\begin{tabular}{ll}
\hline A. palaestinum extract & $\begin{array}{l}\mathrm{IC}_{50} \text { value }(\mu \mathrm{g} / \mathrm{ml}), \\
\pm \mathrm{SD}\end{array}$ \\
\hline Fresh Solomon's lily leaves extract & $45.7 \pm 1.47$ \\
Boiled Solomon's lily leaves extract & $31.62 \pm 3.52$ \\
Oven dried (roasted) Solomon's lily leaves extract & $14.55 \pm 2.06$ \\
Shade dried Solomon's lily leaves extract & $63.09 \pm 2.38$ \\
\hline
\end{tabular}

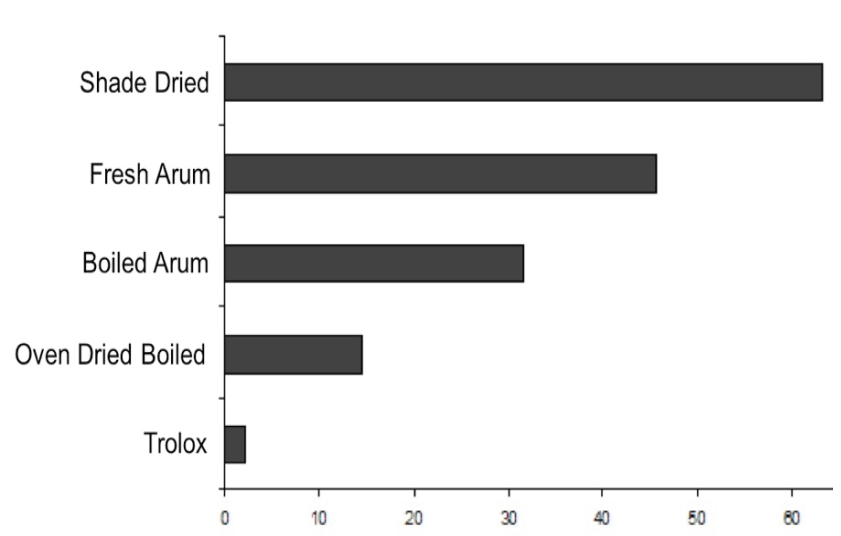

Figure 3. $\mathrm{IC}_{50}$ Value for Trolox and different A. palaestinum extract

\subsection{ET assessment}

Three prepared Solomon's lily products were included in this study. Principal component analysis (PCA) showed a clear discrimination of the samples as shown in Figure 4. Two major components were sufficient for describing the total variation of the data. The first principal component (PC1)

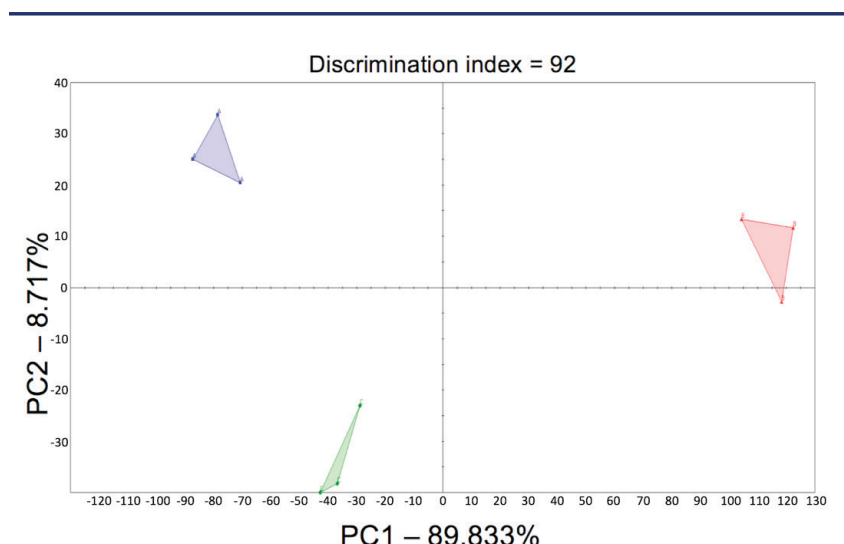

Figure 4. In vitro taste assessment of cooked and fresh Solomon's lily using ET and principal component analysis 
explained $79.4 \%$ and the second principal component (PC2) explained 20.4\%. The two PCs explained about $100 \%$.

\section{DISCUSSION}

In the entire world, tremendous resources are being invested in diagnosis, prevention and treatment of cancer and degenerative cardiovascular disease by using safety edible and medicinal plants.

Discovering and screening for potential anticancer and antioxidant agents from natural edible plants still in the recent time the main scope for many of the nutraceutical and pharmaceutical institutions [26, 27]. In a study which was conducted by Jaradat and Abualhasan, they found that various Solomon's lily species such as $A$. Dioscorides, $A$. elongatum, and $A$. hygrophilum have more potent antioxidant activity in comparison with the studied Solomon's lily species. Their values were 6.7, 4.7, and $6.9 \mu \mathrm{g} / \mathrm{ml}$, respectively [28], in comparison with fresh, boiled, oven dried, and shade dried Solomon's lily species, they were $45.7,31.6,14.5$, and $63.1 \mu \mathrm{g}$ $/ \mathrm{ml}$, respectively. In another study which was conducted by Al-Mustafa and Al-Thunibat [20], they found that the $\mathrm{IC}_{50}$ of the methanolic extraction of A. palaestinum was $24.3 \pm 1.0 \mathrm{ug} /$ $\mathrm{ml}$, while our results were $45.7,31.6,14.5$, and $63.1 \mu \mathrm{g} / \mathrm{ml}$ for the fresh, boiled, oven dried, and shade dried A. palaestinum species, respectively. These results showed that the boiled and shade dried methods were less potent, while the oven dried method was more potent as an antioxidant in comparison to previous studies [20].

Evaluation of taste by ET revealed a significant difference between these products ( $\mathrm{p}$-value $<0.05$ ). The following test describes three parameters, which are distance, $\mathrm{p}$-value, and pattern discrimination index (\%). The lower the distance between samples the lower the difference in the taste between them (Figure 4). Moreover, the ET calculates the \% pattern of discrimination between the tested samples. This index takes into account the difference between the centers of gravity and dispersion of each group. The closer the index to $100 \%$, the greater the distance between the centers of gravity and the smaller the dispersion within groups (Alpha MOS, 2009). As it can be seen from the results in Figure 4, the distance between groups was different. In fact, the distance between A and C was 73.85, while between B and C it was 156 and between A and $B$ it was 195 . This may indicate higher taste similarity between the first two products ( $A$ and $C$ ) than between $B$ and $\mathrm{C}$ or between $\mathrm{A}$ and $\mathrm{B}$. Moreover, the pattern discrimination indexes between $\mathrm{A}$ and $\mathrm{C}, \mathrm{B}$ and $\mathrm{C}$ and between $\mathrm{A}$ and $\mathrm{B}$ were $88.16 \%, 96.36 \%$, and $98 \%$, respectively, which suggests that A and $\mathrm{C}$ are the closest taste since they had the shorter distance and the lowest \% index of discrimination pattern. All these comparisons were statistically significant since the p-values were $<0.05$ in all cases. Therefore, the cooking method would be a suitable tool to minimize the numbing taste of Solomon's lily, but it may negatively impact the phytochemical and therapeutic outcome of this important plant. In fact, it may

Table 4. Percentage inhibition activity by Trolox and different A. palaestinum Extracts

\begin{tabular}{|c|c|c|c|c|c|}
\hline $\begin{array}{l}\text { Conc. } \\
\mu \mathrm{g} / \mathrm{ml}\end{array}$ & $\begin{array}{l}\text { \% inhibition by Trolox, } \\
\pm \text { SD }\end{array}$ & $\begin{array}{l}\% \text { inhibition by fresh } \\
\text { Solomon's lily leaves } \\
\text { extract, } \pm \text { SD }\end{array}$ & $\begin{array}{l}\text { \% inhibition by } \\
\text { Solomon's lily leaves } \\
\text { oven dried extract, } \\
\pm \text { SD }\end{array}$ & $\begin{array}{l}\% \text { inhibition by } \\
\text { Solomon's lily } \\
\text { leaves shade dried } \\
\text { extract, } \pm \text { SD }\end{array}$ & $\begin{array}{l}\% \text { inhibition by } \\
\text { Solomon's lily leaves } \\
\text { boiled extract, } \pm \text { SD }\end{array}$ \\
\hline 1 & $38.62 \pm 1.23$ & $30.86 \pm 1.22$ & $32.3 \pm 2.33$ & $28.98 \pm 2.22$ & $29.93 \pm 1.1$ \\
\hline 2 & $49.53 \pm 1.78$ & $32.93 \pm 1.32$ & $32.69 \pm 2.12$ & $28.98 \pm 2.35$ & $29.93 \pm 1.71$ \\
\hline 3 & $59.81 \pm 1.36$ & $32.93 \pm 1.36$ & $34.93 \pm 2.22$ & $31.3 \pm 2.65$ & $29.93 \pm 1.33$ \\
\hline 5 & $78.81 \pm 2.25$ & $38.76 \pm 1.55$ & $34.93 \pm 1.98$ & $33.62 \pm 2.56$ & $34.47 \pm 1.22$ \\
\hline 7 & $88.16 \pm 2.21$ & $38.76 \pm 1.84$ & $35.26 \pm 1.52$ & $34.2 \pm 2.31$ & $34.47 \pm 1.35$ \\
\hline 10 & $97 \pm 2.01$ & $43.12 \pm 1.55$ & $41.34 \pm 2.51$ & $34.2 \pm 2.65$ & $34.47 \pm 2.01$ \\
\hline 20 & $97 \pm 2.33$ & $43.12 \pm 1.51$ & $45.19 \pm 2.1$ & $34.2 \pm 2.67$ & $46.49 \pm 2.31$ \\
\hline 30 & $97.5 \pm 2.12$ & $48.32 \pm 1.09$ & $48.39 \pm 2.21$ & $41.1 \pm 2.69$ & $46.49 \pm 2.36$ \\
\hline 40 & $98.76 \pm 2.14$ & $48.32 \pm 1.52$ & $53.84 \pm 1.98$ & $42.31 \pm 2.35$ & $52.2 \pm 2.37$ \\
\hline 50 & $98.76 \pm 2.11$ & $51.23 \pm 1.33$ & $71.32 \pm 1.77$ & $51.01 \pm 2.13$ & $52.2 \pm 1.74$ \\
\hline 80 & $98.76 \pm 2.35$ & $51.34 \pm 1.58$ & $77.42 \pm 1.68$ & $51.01 \pm 1.99$ & $60.11 \pm 2.39$ \\
\hline 100 & $98.76 \pm 2.41$ & $51.34 \pm 1.74$ & $88.56 \pm 2.28$ & $56 \pm 2.02$ & $60.11 \pm 2.33$ \\
\hline
\end{tabular}


be a relationship between the taste and the antioxidant activity. Considering both $\mathrm{A}$ and $\mathrm{C}$ were subjected to harsher preparation conditions than $\mathrm{C}$. This may cause a loss of phytochemical agents that are responsible for the antioxidant activity during the cooking and shade drying of the leaves; as a result, they showed closer antioxidant activity as can be shown in Table 4.

\section{CONCLUSION}

The cooked and dried Solomon's lily showed lower numbing taste as revealed by ET. The antioxidant activities showed a marked correlation with the total phenolic contents. At the same time, total phenols and antioxidant activity depend on the cooking or the plant's preparation method. However, the oven dried preparing method (home roasting) for Solomon's lily is the most efficient method for consumption or preparing bioactive supplements for nutraceutical and pharmaceutical supplements.

\section{MATERIALS AND METHODS}

\subsection{Collection and preparing plant materials}

Arum palaestinum leaves were collected in March 2015 from the mountains of Bethlehem and Jerusalem regions of the West Bank/Palestine. The plant was botanically identified in the Department of Pharmacy at An-Najah National University. A voucher specimen was deposited in the Herbarium of the Pharmaceutical Chemistry and Technology Division (Laboratory of Pharmacognosy). The Arum palaestinum herbarium code is (Pharm-PCT-246).

\subsection{Solomon's lily leaves experimental samples preparing}

\subsubsection{Shade dried Solomon's lily leaves}

The leaves were washed several times using distilled water and then dried in the shade at room temperature until all the plant's parts became well dried. After drying, the plant materials were powdered well by using a grinder and placed into a well-closed container.

\subsubsection{Fresh Solomon's lily leaves}

The leaves were washed several times using distilled water, cut in small slices and kept in the refrigerator for further use.

\subsubsection{Roasted Solomon's lily leaves (oven dried method)}

The leaves were washed several times using distilled water and then dried in the oven at $150{ }^{\circ} \mathrm{C}$ for 5 minutes, then it was powdered well by using a grinder and placed into a wellclosed container.

\subsubsection{Boiled Solomon's lily leaves}

The fresh Solomon's lily leaves were prepared and cooked in the same way as for consumption. In brief, the fresh green leaves were cleaned and washed several times using distilled water, and then cut into small pieces. 10 grams of them placed in the beaker with $100 \mathrm{ml}$ milli-Q water and boiled for 30 minutes, the produced mixture kept under the hood until it dried. Then it maintained in a well-closed container for further use.

\subsection{Instrumentation}

An alpha-Astree (Alpha MOS, Toulouse, France) was used to assess the taste. It is composed of seven sensors. The ET was equipped with a 16-position auto-sampler, an automatic stirrer, and an $\mathrm{Ag} / \mathrm{AgCl}$ reference electrode. For multivariate data analysis a software package (chemometrics) (Alpha MOS, Toulouse, France), which also automatically collected and stored the sensors' outputs signal (Alpha MOS, 2009) was used.

Shaker device (Memmert shaking incubator, Germany), rotary evaporator (Heidolph OB2000 Heidolph VV2000, Germany), spectrophotometer (Jenway 7135, England), grinder (Moulinex model, Uno, China), balance (Rad wag, AS 220/c/2, Poland), filter paper (Machinery-Nagel, MN 617 and Whatman no.1, USA), were used for this study.

\subsection{Chemical Reagents}

\subsubsection{For antioxidant evaluation:}

Methanol was purchased from Lobachemie (India). (DPPH) 2, 2-Diphenyl-1-picrylhydrazyl was ordered from Sigma-Aldrich (Germany). Trolox (6-hydroxy - 2, 5, 7, 8 tetramethychroman-2 carboxylic acid) was purchased from Sigma-Aldrich (Denmark).

\subsubsection{For total phenolic content:}

Folin-Ciocalteu and $\mathrm{NaHCO}_{3}$ reagents were purchased from Sigma Aldrich(Germany), and methanol purchased from Lobachemie (India).

\subsection{Preparation of plant extracts for antioxidant evaluation}

About $10 \mathrm{~g}$ of the grounded plant was soaked in 0.1 Liter of methanol (99\%) and put in a shaker device at 100 rounds per minute for 72 hours at room temperature, and then stored in the refrigerator for four days to minimize any potential degradation of the phytochemicals. The extracts were then filtered using filter papers and concentrated under vacuum on a rotator evaporator. The crude extract was stored at -4 ${ }^{\circ} \mathrm{C}$ for further use. 


\subsection{Antioxidant activity}

A stock solution of a concentration of $1 \mathrm{mg} / \mathrm{ml}$ in methanol was firstly prepared for the plant four samples extracts and Trolox. The working solutions of the following concentrations $(1,2,3,5,7,10,20,30,40,50,80,100 \mu \mathrm{g} /$ $\mathrm{ml}$ ) were prepared by serial dilution with methanol from the stock solution. DPPH was freshly prepared at a concentration of $0.002 \% \mathrm{w} / \mathrm{v}$. The DPPH solution was mixed with methanol and the above-prepared working concentration in a ration of 1:1:1 respectively. The spectrophotometer was zeroed using methanol as a blank solution. The first solution of the series concentration was DPPH with methanol only. The solutions were incubated in the dark for 30 minutes at room temperature before the absorbance readings were recorded at $517 \mathrm{~nm}$. The percentage of antioxidant activity of the Solomon's lily leaves four samples, and the Trolox standards were calculated using the following formula [29]:

Percentage of inhibition of DPPH activity $(\%)=(\mathrm{A}-\mathrm{B}) / \mathrm{A}$ $\times 100 \%$

Where:

$\mathrm{A}=$ optical density of the blank,

$\mathrm{B}=$ optical density of the sample.

The antioxidant half maximal inhibitory concentration $\left(\mathrm{IC}_{50}\right)$ for the plant samples and the standard were calculated using BioDataFit edition 1.02 (data fit for biologist).

The antioxidant activity was reported as a percentage of inhibition. The inhibition of Solomon's lily leaves four samples, and Trolox standard at different concentration was plotted and tabulated, and the $\mathrm{IC}_{50}$ for each of them was calculated using the BioDataFit fitting program in which the sigmoidal fitting model was the adapted model.

\subsection{Determination of total phenolic content in the different plant extracts}

Total phenolic content in the plant four samples methanolic extracts was determined using spectrophotometric method [30] with some modifications. $1 \mathrm{mg} / \mathrm{ml}$ aqueous solutions for methanolic extract were prepared in the analysis. The reaction mixture was prepared by mixing $0.5 \mathrm{ml}$ of plant extract from four samples solution, $2.5 \mathrm{ml}$ of $10 \%$ FolinCiocalteu's reagent dissolved in water and $2.5 \mathrm{ml}$ of $7.5 \%$ of the $\mathrm{NaHCO}_{3}$ aqueous solution.

The four Solomon's lilyleaves samples were after that incubated in a thermostat at $45^{\circ} \mathrm{C}$ for $45 \mathrm{~min}$ then the absorbance was estimated using spectrophotometer at wavelength $765 \mathrm{~nm}$. All the four plant samples were prepared in triplicate for each analysis, and the mean value of absorbance was obtained, and the same procedure was repeated for the standard solution of gallic acid, and the calibration line was construed. Based on the measured absorbance, the concentration of gallic acid equivalent expressed regarding ( $\mathrm{mg}$ of $\mathrm{GA} / \mathrm{g}$ of extract).

\subsection{In vitro assessment of taste using ET}

Based on the manufacturer's recommendation, before samples were analyzed, the seven sensors were gone through conditioning, calibration and diagnostic process. Cleaning of the sensor array was done between each measurement using pure distilled water. Three samples of Solomon's lily were mixed with sufficient volume of distilled water. Each sample was measured in triplicate. Data acquisition and data processing was achieved with AlphaSoft software. Multivariate data analysis was used to analyze data.

\section{Authorship statement}

M.Q., N.J. conceived the concept and designed the study; Supervision - M.Q., N.J.; Resource - N.J., A.Z., Materials N.J., A.Z.; Data Collection and/or Processing - M.Q., N.J.,

A.Z., N.K., A.N., F.H.; Analysis and/or Interpretation - M.Q., N.J., A.Z., N.K., A.N., F.H.; Literature Search - M.Q., N.J., A.Z., N.K., A.N., F.H.; Writing - M.Q., N.J., A.Z.; Critical Reviews - M.Q., N.J., A.Z.

\section{Conflict of interest statement}

The authors declared no conflict of interest in the manuscript.

\section{REFERENCES}

[1] Farzaneh V, Carvalho IS. A review of the health benefit potentials of herbal plant infusions and their mechanism of actions. Ind Crops Prod. 2015;65:247-258.

[2] Gerber M. Mediterranean Diet and "Morbid" Tissues: History Counts, Future Counts. Ann Nutr Metab. 2013;62:1-90.

[3] El Gharras H. Polyphenols: food sources, properties and applications-a review. Int J Food Sci Tech. 2009;44:2512-2518.

[4] Kumar SK, Suresh M, Kumar SA, Kalaiselvi P. Bioactive compounds, radical scavenging, antioxidant properties and FTIR spectroscopy study of Morinda citrifolia fruit extracts. Int J Curr Microbiol Appl Sci. 2014;3:28-42.

[5] Nile SH, Park SW. Edible berries: Bioactive components and their effect on human health. Nutrition. 2014;30(2):134-144.

[6] Forbes MHC. Gathering in the Argolid: a subsistence subsystem in a Greek agricultural community. Ann N Y Acad Sci. 1976;268:251-264. 
[7] Lairon D, Huber M. Food quality and possible positive health effects of organic products. In: Bellon S, Penvern S, editors. Organic Farming, Prototype for Sustainable Agricultures. Netherlands: Springer; 2014. p. 295-312.

[8] Hadjichambis AC, Paraskeva-Hadjichambi D, Della A, Elena Giusti M, De Pasquale C, Lenzarini C, Censorii E, Gonzales-Tejero MR, Sanchez-Rojas CP, Ramiro-Gutierrez JM, Skoula M, Johnson C, Sarpaki A, Hmamouchi M, Jorhi S, El-Demerdash M, El-Zayat M, Pieroni A. Wild and semidomesticated food plant consumption in seven circumMediterranean areas. Int J ood Sci Nutr. 2008;59:383-414.

[9] Della A, Paraskeva-Hadjichambi D, Hadjichambis AC. An ethnobotanical survey of wild edible plants of Paphos and Larnaca countryside of Cyprus. J Ethnobiol Ethnomed. 2006;2:34.

[10] Bonet MA, VallEs J. Use of non-crop food vascular plants in Montseny biosphere reserve (Catalonia, Iberian Peninsula). Int J Food Sci Nutr. 2002;53:225-248.

[11] Pieroni A, Nebel S, Quave C, Munz H, Heinrich M. Ethnopharmacology of liakra: traditional weedy vegetables of the Arbereshe of the Vulture area in southern Italy. J Ethnopharmacol. 2002;81(2):165-185.

[12] Dogan Y, Ugulu I, Durkan N. Wild edible plants sold in the local markets of Izmir, Turkey. Pakistan J Bot. 2013;45:177-184.

[13] Luczaj L, Pieroni A, Tardío J, Pardo-de-Santayana M, Soukand R, Svanberg I, Kalle R. Wild food plant use in 21st century Europe: the disappearance of old traditions and the search for new cuisines involving wild edibles. Acta Soc Bot Pol. 2012;81(4):359-370.

[14] Farid MM, Hussein SR, Ibrahim LF, El Desouky MA, Elsayed AM, Saker MM. Shoot regeneration, biochemical, molecular and phytochemical investigation of Arum palaestinum Boiss. Afr J Biotechnol. 2014;13(34):3522-3530.

[15] Rivera D, Obon C, Heinrich M, Inocencio C, Verde A, Fajardo J. Gathered mediterranean food plants-ethnobotanical investigations and historical development. Forum Nutr. 2006;59:18-74.

[16] Ali-Shtayeh MS. Use of Complementary and Alternative Medicine, CAM, among Cancer Patients in Northern West Bank, Palestine: Faculty of Graduate Studies, An-Najah National University; 2012.

[17] Oran SA, Al-Eisawi DM. Medicinal plants in the high mountains of northern Jordan. Int J Biodivers Conserv. 2014;6(6):436-443.
[18] Sakthivel K, Guruvayoorappan C. Biophytum sensitivum: Ancient medicine, modern targets. J Adv Pharm Technol Res. 2012;3(2):83-91.

[19] Challinor VL, De Voss JJ. Plant Steroidal Saponins: A Focus on Open-Chain Glycosides. Natural Products. London: Springer; 2013. p. 3225-3250.

[20] Al-Mustafa A, Al-Thunibat O. Antioxidant activity of some Jordanian medicinal plants used traditionally for treatment of diabetes. Pak J Biol Sci. 2008;11(3):351-358.

[21] Parshikov IA, Sutherland JB. The use of Aspergillus niger cultures for biotransformation of terpenoids. Process Biochem 2014;49(12):2086-2100.

[22] Roy A, Gupta S, Hess D, Das KP, Das S. Binding of insecticidal lectin Colocasia esculenta tuber agglutinin (CEA) to midgut receptors of Bemisia tabaci and Lipaphis erysimi provides clues to its insecticidal potential. Proteomics. 2014;14(13-14):1646-1659.

[23] Safari E, Amiri M, Bahador A, Amiri M, Esmaeili D. The study of antibacterial effects of alcoholic extracts of Arum maculatum, Allium hirtifolium and Teucrium polium against nosocomial resistance bacteria. Int J Curr Microbiol App Sci. 2014;3(2):601-605.

[24] Shahidi F, Ho C-T. Phytochemicals and phytopharmaceuticals: The American Oil Chemists Society; 2000.

[25] Minatel IO, Borges CV, Ferreira MI, Gomez HAG, Chen C-YO, Lima GPP. Phenolic Compounds: Functional Properties, Impact of Processing and Bioavailability. London: InTech; 2017.

[26] Cooper R. Green tea and theanine: health benefits. Int J Food Sci Nutr. 2012;63(S1):90-97.

[27] Udayakumar R, Kasthurirengan S, Vasudevan A, Mariashibu TS, Rayan JJS, Choi CW, Ganapathi A, Kim SC. Antioxidant effect of dietary supplement Withania somnifera L. reduce blood glucose levels in alloxan-induced diabetic rats. Plant Foods Hum Nutr. 2010;65(2):91-98.

[28] Jaradat NA, Abualhasan M. Comparison of phytoconstituents, total phenol contents and free radical scavenging capacities between four Arum species from Jerusalem and Bethlehem. Pharm Sci. 2016;22(2):120-125.

[29] Jaradat NA, Damiri B, Abualhasan MN. Antioxidant evaluation for Urtica urens, Rumex cyprius and Borago officinalis edible wild plants in Palestine. Pak J Pharm Sci. 2016;29:325-330.

[30] Jaradat N, Hussen F, Al Ali A. Preliminary phytochemical screening, quantitative estimation of total flavonoids, total phenols and antioxidant activity of Ephedra alata Decne. J Mater Environ Sci. 2015;6(6):1771-1778. 